\title{
Associations between socio-economic status and dietary patterns in US black and white adults
}

\author{
K. P. Kell ${ }^{1 *}$, S. E. Judd ${ }^{2}$, K. E. Pearson ${ }^{1}$, J. M. Shikany ${ }^{3}$ and J. R. Fernández ${ }^{1}$ \\ ${ }^{1}$ Department of Nutrition Sciences, UAB School of Health Professions, 514 Webb Nutrition Sciences Building, \\ 1675 University Boulevard, Birmingham, AL 35294, USA \\ ${ }^{2}$ Department of Biostatistics, UAB School of Public Health, RPHB 327G, 1665 University Boulevard, Birmingham, \\ AL 35294, USA \\ ${ }^{3}$ Division of Preventive Medicine, UAB School of Medicine, MT 619, 1717 11th Avenue South, Birmingham, AL 35294, USA \\ (Submitted 9 July 2014 - Final revision received 10 February 2015 - Accepted 3 March 2015 - First published online 14 April 2015)
}

\begin{abstract}
Socio-economic status (SES) has been associated with measures of diet quality; however, such measures have not directly captured overall eating practices in individuals. Based on the factor analysis of fifty-six food groups from FFQ, associations between patterns of food consumption and SES were examined in a nationwide sample of 17062 black (34.6\%) and white participants (age $>45$ years) from the REasons for Geographic And Racial Differences in Stroke (REGARDS) study. Logistic regression models adjusted for age, sex, racial group and geographic region were used to examine adherence to five emergent dietary patterns (convenience, plant-based, sweets/ fats, southern and alcohol/salads) according to four levels each of individual education, household income and community-level SES. Further models assessed adherence to these dietary patterns by racial group, and an overall model including both racial groups examined whether the relationships between SES and adherence to these dietary patterns differed among black and white participants. For all the three measures of SES, higher SES had been associated with greater adherence to plant-based and alcohol/salads patterns, but lower adherence to sweets/fats and southern patterns. Statistically significant differences between black and white participants were observed in the associations between household income and adherence to alcohol/salads, individual education and adherence to plant-based and sweets/ fats, and community SES and adherence to convenience patterns. As adherence to dietary patterns has been shown to be associated with health outcomes in this population (e.g. stroke), the present study offers valuable insight into behavioural and environmental factors that may contribute to health disparities in the diverse US population.
\end{abstract}

Key words: Socio-economic status: Diet: Race

Health disparities in the USA are notable among groups of differing socio-economic status (SES) and race ${ }^{(1-4)}$. While various explanations have been given for these disparities, both biological and non-biological ${ }^{(5-12)}$, a recurring and aetiologically relevant theme has been differences in diet $^{(13-20)}$. In order to ameliorate diet-mediated health disparities, it is necessary to identify diets that are associated with given health outcomes (e.g. CVD) and to recognise where disparities exist in the selection and adherence to the mentioned dietary patterns.

Previous studies investigating the associations between diet, race and SES have assessed diet in various ways. Earlier work has focused on examining individual nutrients, as well as groupings of nutrients, both macro and micro ${ }^{(13,14)}$. While scientifically and physiologically relevant, this approach does not reflect the manner in which most individuals select and consume foods.
In order to assess dietary intake more holistically, other researchers have used hypothesis/investigator-driven (a priori) dietary indices in their analyses, which take into consideration patterns of foods consumed together ${ }^{(16,18,20)}$. More recently, datadriven/hypothesis neutral (a posteriori) dietary patterns have been used to analyse these relationships, with dietary patterns serving as a proxy for a variety of factors that influence how individuals consume foods, including social, cultural and financial contributors ${ }^{(15,17,19)}$. However, limited research has been conducted on how an individual's racial group and SES may affect adherence to dietary pattern, especially patterns demonstrated to be related to health outcomes.

The present team of investigators have previously shown that dietary pattern adherence is associated with the risk of incident stroke, contributing to an excess risk in black Americans

Abbreviations: REGARDS, REasons for Geographic And Racial Differences in Stroke; SES, socio-economic status.

*Corresponding author: K. P. Kell, fax: +1 205975 2540, email kpkell@uab.edu 
compared with white Americans ${ }^{(21)}$. The present study seeks to advance this investigation by using the dietary patterns from our previous study to examine the relationships between SES and food choice and how these relationships may differ according to race. Although adherence to only some of the dietary patterns has been significantly associated with the risk of incident stroke (increased risk for southern and reduced risk for plant-based and sweets/fats patterns), all previously derived patterns were used in the present study as our team's examinations of potential associations between dietary patterns and CVD are ongoing, and may yield further insights germane to the findings of the present study. The population used for the present study is especially well suited to this endeavour as it is quite large, nationwide, includes persons of varying levels of SES (both individual-level and community-level indicators) and includes a percentage of black participants (34.6\%) large enough to explore racial differences.

\section{Methods}

\section{Study design}

The REasons for Geographic And Racial Differences in Stroke (REGARDS) study is observational in nature and comprised a population-based random sample ( $n$ 30239) of men and women of black and white racial groups over the age of 45 years $^{(22)}$. The original intent of this study was to elucidate the factors that increase an individual's risk of having a stroke. Recruitment occurred between January 2003 and October 2007, and the baseline data used in the present analyses were cross-sectional in nature; however, the study is ongoing. A related list from the same vendor used by the US Behavioral Risk Factor Surveillance System was employed to recruit individuals. The study intentionally oversampled both blacks and residents of the stroke belt, a region of the southeastern USA where individuals have a substantially increased risk for stroke (Alabama, Arkansas, Georgia, Louisiana, Mississippi, North Carolina, Tennessee and South Carolina). Initial contact with participants was conducted via a mass mailing to inform participants that they would be contacted via telephone to discuss about their participation. This call lasted approximately $45 \mathrm{~min}$, and data on self-reported race, risk factor characterisation, SES and medical history were collected. An in-home visit by a trained health professional followed the phone session, during which they obtained written consent and blood and urine samples. The present study was conducted according to the guidelines laid down in the Declaration of Helsinki, and all procedures involving human subjects were approved by the Institutional Review Board at all participating institutions. Written informed consent was obtained from all participants.

\section{Analysis variables}

Socio-economic status: measurements utilised. The present study assessed SES using education, income and a community-level index ${ }^{(23)}$. Education is reasonably well stable into adulthood $^{(24)}$ (matching the composition of the REGARDS population), and has been shown to capture lifestyle/ behavioural practices ${ }^{(24)}$. Income can influence access to goods such as healthful foods ${ }^{(24)}$, and has been shown to affect diet independently of education ${ }^{(25)}$. The communitylevel index used in the present study included measures of assets, home value and occupational prestige (in addition to income and education) ${ }^{(23)}$. These additional measures are informative in that: (1) assets may help an individual successfully weather financial storms better than income alone ${ }^{(24)}$; (2) one's home is typically the largest asset and its value has been shown to be associated with health behaviours and outcomes $^{(26)}$; (3) occupational prestige can be demonstrative of an individual's standing in society and allostatic load independently of income ${ }^{(24,27)}$. Including all these measures into a composite index at the community level offers an additional insight by revealing where characteristics of an individual's community may uniquely influence health behaviours vis-àvis an individual's personal/family characteristics ${ }^{(28)}$; furthermore, such indices are being increasingly used in attempts to capture the polyfaceted nature of SES ${ }^{(29)}$.

Assessment of individual education and household income. The level of education achieved and annual household income were self-reported during the initial phone interview session. Annual income was categorised into four groups: up to $\$ 20000 ; \$ 20000-\$ 34999 ; \$ 35000-\$ 74999 ; \$ 75000+$. The four levels of education response options were less than high school (non-high school graduate), high school graduate or equivalent certification, some college and college graduate or above. Participants could refuse to provide information on both income and education.

Assessment of community-level socio-economic status. The geographical area used to assess community-level SES was the US census block group (units averaging 1000 individuals). Using the 2000 US census data, the method developed by Diez-Roux et al. ${ }^{(23)}$ was employed to assess communitylevel SES through six representative measures of education, wealth/income and occupational prestige. Two of these measures are given as dollar values: Median household income and median value of housing units. The other four measures are given as percentages: households with interest, dividend or rental income; adults who completed high school; adults who completed college; and residents employed in executive, managerial or professional occupations. $z$ Scores were calculated for each measure and then added together to create a comprehensive score, with the lower number representing lower SES. To reflect the structure of the individuallevel indicators of income and education, this variable was transformed into a categorical variable with four quartiles.

Dietary assessment. The Block98 FFQ was given to the participants during the in-home visit with detailed directions on how to complete it and instructions to mail all forms to the REGARDS Coordinating Center at the University of Alabama at Birmingham. The Block98 FFQ (www.NutritionQuest.com) is a well-validated instrument for measuring a majority of nutrients ${ }^{(30)}$, and other versions of the FFQ have been further validated in diverse populations ${ }^{(31)}$. The Block98 FFQ used in REGARDS study was developed by Block Dietary Data Systems and distributed by NutritionQuest. The Block98 FFQ includes 150 multiple-choice questions to 
obtain information about the frequency and portion of food consumed, as well as preparation of 107 food items. Forms were collected, scanned and verified by at least two trained personnel at the REGARDS Coordinating Center, the results of which were sent to NutritionQuest for scoring and quantification of intake.

Dietary pattern derivation. Using the original 107 food items, fifty-six food groups were constructed based on the criteria such as nutrient similarities, culinary use and previous studies $^{(21)}$. These fifty-six food groups were then used to derive the dietary patterns in the REGARDS cohort with FFQ data ( $n$ 21636) obtained via a form of exploratory factor analysis, i.e. principal component analysis (the detailed description of the dietary pattern derivations in the REGARDS study has been published $\left.{ }^{(21)}\right)$. A random split sample method was used to validate the dietary patterns and ensure their ability to be replicated. The second half of the sample was used to carry out confirmatory factor analysis to validate the principal component analyses, and only food groups with absolute value loadings exceeding $0 \cdot 20$ for a given factor were included in the initial confirmatory factor analysis model. From these analyses, five dietary patterns emerged: convenience, plantbased, sweets/fats, southern and alcohol/salads (see Table 1 for the top ten factor loadings, see online Supplementary Table S1 for a more comprehensive list). For each participant in the study, the factor loading of each food group was multiplied by the average consumption of each food group in order to calculate their factor scores for each dietary pattern. Adherence to dietary pattern was determined by splitting individual factor scores at the median. For a given dietary pattern, participants with a factor score above the median were categorised as high adherers, whereas individuals with a factor score below the median were categorised as low adherers. The adherence of a participant to any given dietary pattern did not preclude the participant from being a high or low adherer to any other dietary pattern.

Analytic sample. The total sample size used in the analyses was 17062 (Table 2). The total sample size of the original REGARDS study (2003-7) was 30183 , but was reduced for our analyses due to unavailable data on FFQ ( $n$ 8547), as well as measures of SES ( $n$ 4574). When compared with the full REGARDS cohort, the analytic sample was not significantly different in terms of age, sex or region. Due primarily to lower rates of return for FFQ among black participants, there was a significantly lower percentage of black participants in the analytic sample $(34.6 \%)$ than in the full REGARDS cohort ( $41.5 \%)$, but still enough to detect racial differences, and still a percentage at least that of the general US population $(13.2 \%)^{(32)}$ (see online Supplementary Table S2). All results (descriptive statistics and logistic regressions) presented in the following section make use of the analytic sample.

\section{Statistical analyses}

Logistic regression was used to assess the associations between adherence to dietary patterns and measures of individual education, household income and community-level SES. Analyses were run with only one dietary pattern per model

。 突 $\frac{\vec{\pi}}{\mathbb{N}}$

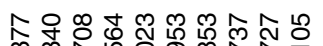

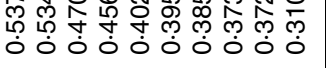

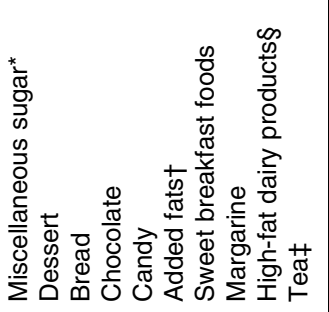


Table 2. Descriptive statistics of the REasons for Geographic And Racial Differences in Stroke (REGARDS) study population $(2003-7)^{*} \dagger$

\begin{tabular}{|c|c|c|c|}
\hline & $\begin{array}{c}\text { Whole } \\
\text { sample } \\
\text { (n 17 062) }\end{array}$ & $\begin{array}{c}\text { Black } \\
(n \text { 5911) }\end{array}$ & $\begin{array}{l}\text { White } \\
(n 11151)\end{array}$ \\
\hline \multicolumn{4}{|l|}{ Age } \\
\hline Mean & 64.7 & 63.5 & $65 \cdot 3$ \\
\hline SD & $9 \cdot 3$ & 8.9 & $9 \cdot 4$ \\
\hline \multicolumn{4}{|l|}{ Race } \\
\hline Black & $34 \cdot 6$ & & \\
\hline \multicolumn{4}{|l|}{ Sex } \\
\hline Female & 54.4 & 65.0 & $48 \cdot 8$ \\
\hline \multicolumn{4}{|l|}{ Region } \\
\hline Stroke belt & 33.9 & $32 \cdot 4$ & $34 \cdot 7$ \\
\hline Buckle & $21 \cdot 3$ & $18 \cdot 2$ & $22 \cdot 9$ \\
\hline Non-stroke belt & $44 \cdot 8$ & $49 \cdot 4$ & $42 \cdot 4$ \\
\hline \multicolumn{4}{|l|}{ Personal education } \\
\hline$<$ High school & $9 \cdot 1$ & $14 \cdot 8$ & $6 \cdot 0$ \\
\hline High school & 24.9 & $26 \cdot 8$ & $23 \cdot 8$ \\
\hline Some college & $27 \cdot 7$ & $29 \cdot 3$ & $26 \cdot 9$ \\
\hline College+ & 38.4 & $29 \cdot 1$ & $43 \cdot 3$ \\
\hline \multicolumn{4}{|l|}{ Personal income } \\
\hline$\$ 20 \mathrm{~K}$ & $17 \cdot 9$ & $28 \cdot 0$ & $12 \cdot 5$ \\
\hline$\$ 20 \mathrm{~K}-\$ 34 \mathrm{~K}$ & $27 \cdot 1$ & $30 \cdot 3$ & $25 \cdot 5$ \\
\hline$\$ 35 \mathrm{~K}-\$ 74 \mathrm{~K}$ & $35 \cdot 6$ & $31 \cdot 3$ & $37 \cdot 8$ \\
\hline$\$ 75 \mathrm{k}+$ & $19 \cdot 4$ & 10.5 & $24 \cdot 1$ \\
\hline \multicolumn{4}{|l|}{ Community-level SES index } \\
\hline Quartile 1 & $25 \cdot 0$ & $45 \cdot 0$ & 14.4 \\
\hline Quartile 2 & $25 \cdot 0$ & $27 \cdot 8$ & 23.5 \\
\hline Quartile 3 & $25 \cdot 0$ & $18 \cdot 7$ & $28 \cdot 3$ \\
\hline Quartile 4 & $25 \cdot 0$ & 8.5 & 33.7 \\
\hline Current smoker & $14 \cdot 0$ & 17.5 & $12 \cdot 2$ \\
\hline Obese $\left(\mathrm{BMI} \geq 30 \mathrm{~kg} / \mathrm{m}^{2}\right)$ & $37 \cdot 0$ & 48.8 & 30.7 \\
\hline $\begin{array}{l}\text { Sedentary } \\
\quad(\geq 4+h / d \text { of screen time })\end{array}$ & $30 \cdot 4$ & $43 \cdot 3$ & $23 \cdot 6$ \\
\hline
\end{tabular}

SES, socio-economic status.

*Values were significantly different between both races for all variables shown $\left(P<0.05 ; \chi^{2}\right.$ tests were performed for all categorical variables, and Student's $t$ test for continuous variables).

†Unless otherwise indicated, values given are percentages.

(the dependent variable in each model), and were first run in the overall population sample, and then by racial group. In the overall model, covariates included age, racial group, sex and region (stroke belt, stroke buckle, defined as 153 counties in the coastal plains of North Carolina, South Carolina and Georgia, and non-stroke belt), whereas in the models analysed by racial group, covariates included age, sex and region. Three interaction variables were created to test for interactions between racial group and socio-economic variables: race $x$ individual education; race $\times$ household income; race $\times$ community-level SES. When the interaction terms were statistically significant, analyses were stratified by racial group. A significant interaction was considered to be $P<0.05$.

All assessments of the significance of associations were taken from the Type III analysis of effects/Wald $\chi^{2}$ test, and OR estimates were obtained from the point estimate and 95\% Wald confidence limits. The SAS version 9.3 (SAS Institute, Inc.) was used for all analyses.

\section{Results}

The average age of the study sample was 64.7 years, with $54.4 \%$ being females (Table 2). In the sample, $34.6 \%$ of the population was black, $38.4 \%$ were in the highest bracket of education and $19.4 \%$ were in the highest bracket of income.

The associations between SES measures and adherence to dietary patterns for the overall sample, i.e. both black and white participants, are presented in Table 3 as OR with CI. Those participants in the highest $v$. lowest tiers of all SES measures - household income, individual education and community-level SES - were significantly more likely to adhere to plant-based and alcohol/salads dietary patterns $(\mathrm{OR}>1)$, but less likely to adhere to either sweets/fats or southern dietary patterns $(\mathrm{OR}<1)$. Additionally, participants in the highest $v$. lowest tiers of both individual education and community-level SES, but not household income, were more likely to adhere to the convenience dietary pattern.

Interactions between racial group and socio-economic variables were tested in the overall sample using the following interaction terms in the logistic regression models: race $X$ individual education; race $\times$ household income; race $\times$ community-level SES. As denoted by asterisks in Table 3, statistically significant differences between black and white participants were observed in the associations between household income and adherence to alcohol/salads, individual education and adherence to plant-based and sweets/fats, and community SES and adherence to convenience patterns. Given the significant racial differences in the associations between measures of SES and adherence to dietary patterns, these associations were analysed for each racial group. Although the magnitude of adherence differed significantly by racial group for some dietary patterns and measures of SES, the direction of adherence was the same for both black and white participants (Table 4).

When further including lifestyle/demographic variables such as smoking, physical inactivity and BMI (online Supplementary Tables S3 and S4), all of these associations were maintained except that those participants in the highest $v$. lowest tiers of income (overall sample only) were now more likely to adhere to the convenience pattern, but no longer or less likely to adhere to the plant-based dietary pattern. These shifts are not surprising given the close proximity of the previous CI to 1 , and the fact that health behaviours tend to be related to one another ${ }^{(33,34)}$.

\section{Discussion}

Although a number of studies have investigated the associations between diet, race and SES, the majority of research has assessed diet either according to its component nutrients $^{(35-37)}$, or using prescribed, a priori dietary indices $^{(16,18,20,38)}$. These assessments, while informative in their own right, may not entirely incorporate or reflect underlying patterns of food choice. By using a posteriori dietary patterns, researchers are able to see how foods group together in the diet and which foods make up a large portion of the diet $^{(39)}$, allowing for more effective behavioural and policybased interventions. Using a large nationwide sample and $a$ posteriori dietary patterns, some of which have previously been demonstrated to be associated with the risk of incident stroke $^{(21)}$, the present study examined how SES, 
Table 3. Logistic regression of dietary patterns v. socio-economic status (SES) indicators in the REasons for Geographic And Racial Differences in Stroke (REGARDS) study population (2003-7)

(Odds ratios and $95 \%$ confidence intervals, $n$ 17062)

\begin{tabular}{|c|c|c|c|c|c|c|c|c|c|c|}
\hline & \multicolumn{2}{|c|}{ Convenience } & \multicolumn{2}{|c|}{ Plant-based } & \multicolumn{2}{|c|}{ Sweets/fats } & \multicolumn{2}{|c|}{ Southern } & \multicolumn{2}{|c|}{ Alcohol/salads } \\
\hline & OR & $95 \% \mathrm{Cl}$ & OR & $95 \% \mathrm{Cl}$ & OR & $95 \% \mathrm{Cl}$ & OR & $95 \% \mathrm{Cl}$ & OR & $95 \% \mathrm{Cl}$ \\
\hline \multicolumn{11}{|c|}{ Household income† } \\
\hline$\leq \$ 20 \mathrm{~K}$ & Ref & & Ref & & Ref & & Ref & & Ref & \\
\hline$\$ 20 \mathrm{~K}-\$ 34 \mathrm{~K}$ & 0.96 & $0.87,1.06$ & 1.00 & $0.90,1.10$ & 0.94 & $0.86,1.04$ & 0.74 & $0.66,0.82$ & 1.31 & $1 \cdot 19,1.45$ \\
\hline$\$ 35 \mathrm{~K}-\$ 74 \mathrm{~K}$ & 1.00 & $0.90,1.10$ & 1.09 & $0.99,1.20$ & 0.92 & $0.84,1.02$ & 0.60 & $0.53,0.66$ & 1.68 & $1.52,1.86$ \\
\hline \multirow{2}{*}{\multicolumn{11}{|c|}{$\begin{array}{l}\$ 15 \mathrm{~K}+ \\
\text { Personal education } \dagger\end{array}$}} \\
\hline & & & & & & & & & & \\
\hline$<$ High school & Ref & & Ref & & Ref & & Ref & & Ref & \\
\hline High school & $1 \cdot 10$ & $0.97,1.24$ & $1 \cdot 11$ & $0.99,1.26$ & 0.95 & $0.84,1.07$ & 0.76 & $0.66,0.87$ & $1 \cdot 17$ & $1.03,1.34$ \\
\hline Some college & $1 \cdot 12$ & $0.99,1.27$ & 1.25 & $1.11,1.42$ & 0.89 & $0.79,1.01$ & 0.62 & $0.54,0.71$ & 1.35 & $1.19,1.54$ \\
\hline College+ & $1 \cdot 23$ & $1.08,1.40$ & 1.82 & $1 \cdot 60,2 \cdot 06^{\star}$ & 0.76 & $0.67,0.86^{*}$ & 0.43 & $0.37,0.50$ & 1.50 & $1 \cdot 31,1 \cdot 71$ \\
\hline \multicolumn{11}{|c|}{ Community-level SES†‡ } \\
\hline Quartile 1 & Ref & & Ref & & Ref & & Ref & & Ref & \\
\hline Quartile 2 & 1.09 & $1.00,1.20$ & $1 \cdot 13$ & $1.03,1.23$ & 0.94 & $0.86,1.03$ & 0.74 & $0.67,0.82$ & 1.27 & $1 \cdot 16,1.39$ \\
\hline Quartile 3 & $1 \cdot 19$ & $1.08,1.31$ & 1.22 & $1 \cdot 12,1.34$ & 0.83 & $0.76,0.91$ & 0.52 & $0.47,0.57$ & 1.46 & $1.33,1.60$ \\
\hline Quartile 4 & 1.23 & $1 \cdot 11,1.36^{\star}$ & 1.56 & $1.42,1.72$ & 0.60 & $0.54,0.66$ & 0.35 & $0.31,0.38$ & 2.05 & $1 \cdot 86,2 \cdot 26$ \\
\hline
\end{tabular}

Ref, reference.

*Values were significantly different by race $(P<0.05)$; see Table 4.

† Covariates for income models include age, sex, race, region and education; covariates for education models include age, sex, race, region and income; covariates for community SES models include age, sex, race and region.

$\ddagger$ Community SES $z$ scores were obtained using the six-component method developed by Diez-Roux et al. ${ }^{(23)}$, and then stratified into quartiles. Components included median household income, median value of housing units, percentage of households with interest, dividend, or rental income, percentage of adults who completed high school, percentage of adults who completed college and percentage of residents employed in executive, managerial or professional occupations.

both individual and community level, as well as racial group, may be associated with the dietary patterns that individuals choose to follow.

All measures of SES were positively associated with adherence to a plant-based dietary pattern; however, household income showed the weakest association with adherence to this pattern, leading to the conjecture that education may be a more important determinant of what could be described as a 'healthy' diet than income alone. This finding is echoed by recent work in children demonstrating maternal education to be a more consistent predictor of diet than household income ${ }^{(40)}$.

While both racial groups demonstrated positive associations between individual education and adherence to the plantbased dietary pattern, education in whites was more strongly associated with adherence to this pattern compared with blacks. This finding brings to mind existing racial disparities in educational attainment, namely that the percentage of persons educated at the collegiate level and beyond is higher among whites than blacks ${ }^{(41,42)}$. The racial disparity in plant-based diet adherence, compounded by disparities in educational attainment, may contribute to racial health disparities since consumption of fruits, vegetables and legumes appears similarly beneficial for both black and white Americans $^{(43,44)}$. Although initiatives to close the higher education gap are currently in place, our research evidences the importance of implementing such initiatives as a potential tool to prevent diet-mediated racial disparities in health.

A unique pattern that emerged from the factor analyses was the alcohol/salads pattern. Adherence to this pattern was positively associated with all indicators of SES. The race by household income interaction was significant in this pattern, with greater adherence seen in whites in the highest income category than blacks in the same income category. This racial difference is not entirely surprising given the fact that the percentage of the white population who are current drinkers exceeds that of the black population by $15 \%{ }^{(45)}$. Furthermore, heavy alcohol consumption such as binge drinking has been shown to increase relative to income more in whites than blacks ${ }^{(46,47)}$. Although green salads are a positive component of the alcohol/salads pattern, the results of these analyses, taken in the aforementioned context, reveal the potential need for public health initiatives to encourage responsible consumption of alcohol among higher-earning white Americans.

Our data show that adherence to dietary patterns in both blacks and whites was in the same direction in all significant relationships, but that the magnitude of adherence between the racial groups was different in some instances. This demonstrates that while an individual's racial group may be an influential factor in determining food choice, stark dichotomies are not observed merely due to race.

An important message that can be gleaned from the results of the present study is that SES may supersede culinary traditions in some instances. This is most clearly demonstrated when looking at the southern dietary pattern. In a previous study examining black and white older adults in the southeast, education has been negatively associated with a preference for typical southern foods ${ }^{(48)}$. Our findings support this study, since in every indicator of SES used in the present study, and in both racial groups (no race $\times$ SES indicator interactions were significant), SES was negatively associated with adherence to the southern dietary pattern. The ability of education, income and/or SES to overcome the ties of cultural 
lifestyle observances, especially when those observances could be deleterious to an individual's health, may prove hopeful in public health campaigns (e.g. encouraging those individuals in the lower tiers of SES who are strongly adherent to this pattern to reduce their consumption of fried and processed meats, as well as sugar-sweetened beverages). However, in order for increasing an individual's education to have an independent effect on diet choice, education itself must be the driving force behind this association, perhaps exerting its effect by increasing an individual's health literacy. This relationship, however, remains to be conclusively known, and perhaps educational attainment may be, to some extent, a marker for familial characteristics, or even greater self-efficacy.

The present study was unique due to a confluence of elements. By using dietary patterns previously shown to be associated with the risk of incident stroke ${ }^{(21)}$, the present study was able to address how SES and/or an individual's racial group relate to diet selection, and sheds light on how such disparities in diet may affect disparities in health outcomes observed among such groups. The use of a nationwide data set allows for generalisability beyond the southeastern USA, a region with increased cardiometabolic risk and the original impetus for the REGARDS study. Furthermore, the population included individuals of varying levels of SES (both individual-level and community-level indicators) as well as a substantial number of minority participants (34.6\% black), especially compared with previous studies in this arena. The large number of black participants strengthened the study by providing the power to detect significant interactions between variables within racial groups.

Despite the many strengths of the study, a number of limitations persist. While the FFQ used has been validated in a population similar to that of the present study ${ }^{(31)}$, no selfreported diet measures can perfectly represent actual food consumption, especially when the recall period is an entire year. Self-report was also utilised in the collection of measures of household income and education. Since data on household size were not available, it was not possible to ensure that household income was assessed homogenously across all study participants, and this may have introduced some uncertainty in the analyses using household income. However, given that the relationships between household income and adherence to the dietary patterns mirrored the relationships between the other measures of SES and adherence to the dietary patterns (except for the convenience pattern, which approached significance), this does not appear to be of great concern. Although diet cost has been associated with diet quality in the literature ${ }^{(49-52)}$, data pertaining to food purchases were not available in this sample. As a result, the putative impact of income on food accessibility, and therefore dietary pattern selection, unfortunately could not be directly assessed in this population. Although the sample size for the present study was quite large ( $n$ 17062), almost half of the REGARDS cohort did not have sufficient SES or nutrition data for inclusion in the study (see online Supplementary Table S1). Additional research needs to be conducted in order to more fully understand the underlying reasons behind the associations revealed in the present study, such 
as accessibility to food outlets, time constraints in food preparation, taste preferences, and among others.

The present study provides insight into how groups differing by SES and/or race currently consume food, and serves as a springboard for further elucidation of diet-mediated health disparities. Given the complex nature of diet selection, intervention studies should be designed to more fully isolate the effects of specific SES components. Based on the knowledge gleaned from the present study, as well as future studies, interventions can be more effectively designed to shift individuals' dietary patterns and practices towards those that are healthier. Such interventions may not only ameliorate observed health disparities among groups, but also raise the overall level of health for the general population.

\section{Supplementary material}

To view supplementary material for this article, please visit http://dx.doi.org/10.1017/S0007114515000938

\section{Acknowledgements}

This research project is supported by a cooperative agreement U01 NS041588 from the National Institute of Neurological Disorders and Stroke, National Institutes of Health, Department of Health and Human Service. The content is solely the responsibility of the authors and does not necessarily represent the official views of the National Institute of Neurological Disorders and Stroke or the National Institutes of Health. Representatives of the funding agency have been involved in the review of the manuscript but not directly involved in the collection, management, analysis or interpretation of the data. The authors thank the other investigators, the staff and the participants of the REGARDS study for their valuable contributions. A full list of participating REGARDS investigators and institutions can be found at http://www.regardsstudy.org.

The first author was supported by the following NIH grant mechanisms: NIDDK P30DK056336 and NHLBI T32HL105349.

None of the authors has any conflict of interest to declare.

The authors' contributions are as follows: K. P. K. was involved in the conception and design, analysis and interpretation of the data, drafting and revision of the article, and final approval of the version; S. E. J. was involved in the conception and design, analysis and interpretation of the data, revision of the article, and final approval of the version; K. E. P., J. M. S. and J. R. F. were involved in the interpretation of the data, revision of the article and final approval of the version.

\section{References}

1. CDC (2009) Differences in prevalence of obesity among Black, White, and Hispanic adults - United States, 2006-2008. Morbid Mortal Week Rep 58, 740-744.

2. CDC (2013) CDC Health Disparities and Inequalities Report United States, 2013. Morbid Mortal Week Rep 62, 1-5.

3. NIH (2011) Strategic Plan for NIH Obesity Research. NIH Publication No. 11-5493. Washington, DC: Department of Health and Human Services, National Institutes of Health.
4. Go A, Mozaffarian D, Roger V, et al. (2014) Executive summary: heart disease and stroke statistics - 2014 update: a report from the American Heart Association. Circulation 129, 399-410.

5. Baum A, Garofalo J \& Yali A (1999) Socioeconomic status and chronic stress. Does stress account for SES effects on health? Ann N Y Acad Sci 896, 131-144.

6. Duru O, Harawa N, Kermah D, et al. (2012) Allostatic load burden and racial disparities in mortality. J Natl Med Assoc 104, 89-95.

7. Gordon-Larsen P, Nelson M, Page P, et al. (2006) Inequality in the built environment underlies key health disparities in physical activity and obesity. Pediatrics 117, 417-424.

8. Hutch D, Bouye K \& Skillen E (2011) Potential strategies to eliminate built environment disparities for disadvantaged and vulnerable communities. Am J Public Health 101, 587-595.

9. Islami F, Kahn A, Bickell N, et al. (2013) Disentangling the effects of race/ethnicity and socioeconomic status of neighborhood in cancer stage distribution in New York City. Cancer Cause Control 24, 1069-1078.

10. Mezuk B, Myers J \& Kendler K (2013) Integrating social science and behavioral genetics: testing the origin of socioeconomic disparities in depression using a genetically informed design. Am J Public Health 103, S145-S151.

11. Olden K \& White S (2005) Health-related disparities: influence of environmental factors. Med Clin North Am 89, $721-738$.

12. Snowden L (2012) Health and mental health policies' role in better understanding and closing African American-White American disparities in treatment access and quality of care. Am Psychol 67, 524-531.

13. Aggarwal A, Monsivais P \& Drewnowski A (2012) Nutrient intakes linked to better health outcomes are associated with higher diet costs in the US. PLOS ONE 7, e 37533.

14. Bjørke-Monsen A, Roth C, Magnus P, et al. (2012) Maternal B vitamin status in pregnancy week 18 according to reported use of folic acid supplements. Mol Nutr Food Res 57, 645-652.

15. Cutler G, Flood A, Hannan P, et al. (2011) Multiple sociodemographic and socioenvironmental characteristics are correlated with major patterns of dietary intake in adolescents. J Am Diet Assoc 111, 230-240.

16. García-Arenzana N, Navarrete-Muñoz E, Peris M, et al. (2012) Diet quality and related factors among Spanish female participants in breast cancer screening programs. Menopause 19, 1121-1129.

17. Hare-Bruun H, Togo P, Andersen L, et al. (2011) Adult food intake patterns are related to adult and childhood socioeconomic status. J Nutr 141, 928-934.

18. Hiza H, Casavale K, Guenther P, et al. (2013) Diet quality of Americans differs by age, sex, race/ethnicity, income, and education level. I Acad Nutr Diet 113, 297-306.

19. Nobre L, Lamounier J \& Franceschini SC (2012) Preschool children dietary patterns and associated factors. $J$ Pediatr (Rio J) 88, 129-136.

20. Olmedo-Requena R, Fernández J, Prieto C, et al. (2013) Factors associated with a low adherence to a Mediterranean diet pattern in healthy Spanish women before pregnancy. Public Health Nutr 17, 648-656.

21. Judd SE, Gutiérrez OM, Newby PK, et al. (2013) Dietary patterns are associated with incident stroke and contribute to excess risk of stroke in black Americans. Stroke 44 , 3305-3311. 
22. Howard V, Cushman M, Pulley L, et al. (2005) The reasons for geographic and racial differences in stroke study: objectives and design. Neuroepidemiology 25, 135-143.

23. Diez-Roux A, Kiefe C, Jacobs D, et al. (2001) Area characteristics and individual-level socioeconomic position indicators in three population-based epidemiologic studies. Ann Epidemiol 11, 395-405.

24. Shavers VL (2007) Measurement of socioeconomic status in health disparities research. I Natl Med Assoc 99, $1013-1023$

25. Galobardes B, Morabia A \& Bernstein MS (2001) Diet and socioeconomic position: does the use of different indicators matter? Int J Epidemiol 30, 334-340.

26. Coffee NT, Lockwood T, Hugo G, et al. (2013) Relative residential property value as a socio-economic status indicator for health research. Int J Health Geogr 12, 22

27. Adler NE \& Stewart J (2010) Preface to the biology of disadvantage: socioeconomic status and health. Ann $N Y$ Acad Sci 1186, 1-4.

28. Robert SA (1998) Community-level socioeconomic status effects on adult health. J Health Soc Behav 39, 18-37.

29. Oakes JM \& Rossi PH (2003) The measurement of SES in health research: current practice and steps toward a new approach. Soc Sci Med 56, 769-784.

30. Patterson R, Kristal A, Tinker L, et al. (1999) Measurement characteristics of the Women's Health Initiative food frequency questionnaire. Ann Epidemiol 9, 178-187.

31. Block G, Woods M, Potosky A, et al. (1990) Validation of a self-administered diet history questionnaire using multiple diet records. J Clin Epidemiol 43, 1327-1335.

32. USCB (2013) USA QuickFacts. People QuickFacts. Black or African American alone, percent, 2013. http://quickfacts. census.gov/qfd/states/00000.html (accessed October 2014).

33. Gillman MW, Pinto BM, Tennstedt S, et al. (2001) Relationships of physical activity with dietary behaviors among adults. Prev Med 32, 298-301.

34. Blair SN, Jacobs DR Jr \& Powell KE (1985) Relationships between exercise or physical activity and other health behaviors. Public Health Rep 100, 172-180.

35. Huffman F, Vaccaro J, Zarini G, et al. (2012) Inadequacy of micronutrients, fat, and fiber consumption in the diets of Haitian-, African- and Cuban-Americans with and without type 2 diabetes. Int J Vitam Nutr Res 82, 275-287.

36. Monsivais P, Aggarwal A \& Drewnowski A (2012) Are socioeconomic disparities in diet quality explained by diet cost? J Epidemiol Commun H 66, 530-535.

37. Darmon N \& Drewnowski A (2008) Does social class predict diet quality? Am J Clin Nutr 87, 1107-1117.

38. Monsivais P \& Drewnowski A (2009) Lower-energy-density diets are associated with higher monetary costs per kilocalorie and are consumed by women of higher socioeconomic status. I Am Diet Assoc 109, 814-822.

39. Newby P \& Tucker K (2004) Empirically derived eating patterns using factor or cluster analysis: a review. Nutr Rev $\mathbf{6 2}$, $177-203$.
40. Zarnowiecki D, Ball K, Parletta N, et al. (2013) Describing socioeconomic gradients in children's diets - does the socioeconomic indicator used matter? Int J Behav Nutr Phys Act 11, 44 .

41. USCB (2010) Educational Attainment in the United States: 2010 - Detailed Tables. Table 1. Educational Attainment 601 of the Population 18 Years and Over, by Age, Sex, Race, and Hispanic Origin: 2010. https://www.census gov/hhes/socdemo/education/data/cps/2010/tables.html (accessed October 2014).

42. Aud S, Fox M, Kewal Ramani A (2010) Status and Trends in the Education of Racial and Ethnic Groups (NCES 2010-015). US Department of Education, National Center for Education Statistics. Washington, DC: US Government Printing Office. http://nces.ed.gov/pubs2010/2010015.pdf (accessed October 2014).

43. Kolonel LN, Hankin JH, Whittemore AS, et al. (2000) Vegetables, fruits, legumes and prostate cancer: a multiethnic case-control study. Cancer Epidemiol Biomarkers Prev 9, 795-804

44. Brown LM, Swanson CA, Gridley G, et al. (1998) Dietary factors and the risk of squamous cell esophageal cancer among black and white men in the United States. Cancer Cause Control 9, 467-474.

45. SAMHSA (2007) National Survey on Drug Use and Health Tobacco Product and Alcohol Use. Table 2.46B. HYPERLINK http://oas.samhsa.gov/NSDUH/2k7NSDUH/ tabs/Sect2peTabs43to84.htm\#Tab2.46B (accessed October 2014).

46. Spiegler D (1993) Alcohol Use Among US Ethnic Minorities Research Monograph no. 18. Rockville, MD: US Department of Health and Human Services, National Institute on Alcohol Abuse and Alcoholism. http://books.google.com/books? $\mathrm{hl}=$ en\&lr=\&id=e-i7QN2OJVsC\&oi=fnd\&pg $=$ PP5\&dq=Spiegler+ Diane+(1993)+Alcohol+Use+Among+US+Ethnic+Minorities \&ots=nd5K1osgo3\&sig=4DSsqZcgYsihJl_jIFbWwa5ywPM\#v= onepage \&q\&f=false

47. Orcutt JD \& Rudy DR (2003) Drugs, Alcohol, and Social Problems. Boulder, CO: Rowman \& Littlefield Publishers, Inc.

48. Yang Y, Buys D, Judd S, et al. (2013) Favorite foods of older adults living in the Black Belt Region of the United States. Influences of ethnicity, gender, and education. Appetite $\mathbf{6 3}$, $18-23$.

49. Drewnowski A (2004) Obesity and the food environment dietary energy density and diet costs. Am J Prev Med $\mathbf{2 7}$ 154-162.

50. Drewnowski A \& Darmon N (2005) Food choices and diet costs: an economic analysis. J Nutr 135, 900-904.

51. Drewnowski A, Monsivais P \& Maillot M (2007) Low-energydensity diets are associated with higher diet quality and higher diet costs in French adults. J Am Diet Assoc 107, 1028-1032.

52. Darmon N, Briend A \& Drewnowski A (2004) Energy-dense diets are associated with lower diet costs: a community study of French adults. Public Health Nutr 7, 21-27. 